\title{
POR QUE SOMOS TÃO DISCIPLINARES? ${ }^{1}$
}

\section{Alice Casimiro Lopes}

\section{RESUMO}

Com base na discussão acumulada no campo do currículo sobre organização do currículo escolar, reflito, neste artigo, sobre a disciplinarização do conhecimento que nos constitui como pesquisadores. Por que ainda somos tão disciplinares? Mesmo em um campo no qual o debate crítico sobre as disciplinas é tão acentuado, por que ainda organizamos nossos periódicos, congressos, processos de avaliação nas agências de fomento e aulas de maneira disciplinar? Analiso neste artigo que a resposta a essas questões não é encontrada nas dinâmicas gerais da organização do conhecimento científico, nem pode ser reduzida à dicotomia entre ser contra ou a favor das disciplinas. Defendo como a discussão sobre as disciplinas nos dirige a um debate sobre política e identidade.

\section{PALAVRAS-CHAVE}

Currículo; Disciplina; Hibridismo; Identidade; Política

\section{WHY WE ARE SO STILL DISCIPLINED?}

\begin{abstract}
Based on the accumulation of discussion in the field of the curriculum regarding the school curricular organization itself, I am reflecting in this paper on the disciplinarization of the knowledge that constitutes us as researchers. Why are we still so disciplined in the actual organization of our research? Even in a field where critical debate on the subjects is so strong, why do we still organize our journals, congresses, development agency evaluation processes and classes in such a disciplinary way? I analyze in this paper that the answer to these questions is not found in a general dynamics of organizing scientific knowledge, nor can it be reduced to a dichotomy between being for or against the disciplines. I argue how the discussion on disciplines reminds us of a debate on politics and identities.
\end{abstract}

\section{KEYWORDS}

Curriculum; Discipline; Hybridism; Identity; Politics

\footnotetext{
${ }^{1}$ Versão reduzida do artigo About libraries and identities, p. 1 a 21, 2008, produzido no âmbito da pesquisa Intellectual Advancement Through the Internationalization of Curriculum Studies, coordenada por William Pinar e financiada pelo Social Sciences and Humanities Research Council of Canada.
} 
(...) traçar nitidamente uma fronteira já equivale a ultrapassá-la.

Gaston Bachelard, Études

Quando recebi o convite para focalizar o tema Cooperação Interdisciplinar $e$ produção do conhecimento em Educação ${ }^{2}$, a proposta era a de abordarmos as disciplinas na área, e suas inter-relações, tendo em vista nossa própria produção do conhecimento. Com isso, acabei sendo levada a considerar não apenas as disciplinas acadêmicas e aquelas construídas na pesquisa, mas também as disciplinas escolares, na medida em que trabalho com o campo educacional em uma estreita relação com a escola e seus saberes. Nas pesquisas que desenvolvo no campo do currículo, tenho trabalhado com a distinção entre disciplinas escolares, acadêmicas e científicas, em virtude de seus diferentes processos históricos de constituição e das diferentes finalidades sociais por elas atendidas. Defendo que tal distinção é produtiva nesse campo, por contribuir para o questionamento de uma transposição acrítica de epistemologias e concepções das ciências para a escola (LOPES, 2007, 2008). Neste artigo, contudo, meu foco é deslocado para a abordagem do que há de semelhante entre essas disciplinas. Em outras palavras, focalizo a própria disciplinaridade e os contornos que ela traz para a produção do conhecimento, nos mais diferentes contextos: escolares, acadêmicos e científicos.

Pensando sobre a disciplinaridade, uma metáfora que me vem à mente é a relação estabelecida entre disciplinas e bibliotecas. Marcados por uma formação iluminista, na qual as disciplinas são entendidas como conjuntos de saberes, bem como métodos e dispositivos de pensamento comuns, capazes de produzir e reproduzir esses saberes, muitas vezes consideramos que podemos reunir em nossas mentes, e em nossas estantes, a biblioteca que nos forma em uma dada disciplina. Não se trata da biblioteca de Babel, descrita por Borges ${ }^{3}$, pois a intenção não é a de reunir o universo de todos os livros possíveis, mas de exercer o poder da seleção do que se entende, pelo tempo ou pelo julgamento esclarecido, ou ainda por uma associação dos dois - o tempo parece ser o juiz final do esclarecimento -, como sendo o melhor. Ainda que afirmemos continuamente que os saberes são socialmente construídos,

\footnotetext{
${ }^{2}$ Refiro-me à Sessão Especial Cooperação Interdisciplinar e produção do conhecimento em Educação na $30^{\mathrm{a}}$ Reunião Anual da ANPEd, entre 07 e 10 de outubro de 2007, na qual a apresentei parte da discussão deste texto. ${ }^{3}$ Jorge Luís Borges descreve no conto A Biblioteca de Babel, que consta de seu livro Ficções, a biblioteca que teria todos os possíveis textos escritos e a escrever de toda humanidade. Mas ele nos aponta a ironia da seleção, pois na medida em que a Biblioteca é o Universo infinito de todos os livros possíveis, qualquer seleção dessa biblioteca também é infinita.
} 
muitas vezes nos referimos aos saberes disciplinares como se compusessem um repertório estável. Formados nessa interpretação de cultura como seleção, nos constituímos como ávidos consumidores e leitores e vamos construindo a biblioteca dos nossos sonhos, com maior ou menor sucesso. Aquela biblioteca que não apenas queremos ter e ler, de forma a dominar o corpo disciplinar, mas também aquela que queremos transmitir aos que vêm depois de nós. $\mathrm{Na}$ academia, no processo de produção científica, queremos que nossos orientandos e colaboradores tenham acesso a essa biblioteca. Nas escolas, esperamos que nossos filhos e alunos conheçam o que é entendido como leituras básicas ou fundamentais para garantir o acesso às múltiplas bibliotecas imaginárias que compõem o que se supõe ser o acervo de conhecimento humano.

Por vezes, cuidamos dessa biblioteca com o esmero de Peter $\mathrm{Kien}^{4}$ e chegamos a reificar os livros. Eles se tornam os objetos do conhecimento por excelência, a serem admirados e colecionados em bibliotecas das quais tiramos cotidianamente o pó. Pelos livros, há também quem se afaste do mundo vivido pela via do pensamento tornando-se, como Peter, cabeças sem mundo - e para saber a crise que se estabelece quando cabeças sem mundo se encontram com o mundo sem cabeça, melhor ler a história de Peter no livro de Elias Cannetti.

Nas diferentes ciências, as bibliotecas se especializam de múltiplas formas. O reconhecimento da biblioteca que nos serve é um dos atributos pelos quais somos valorizados na academia. A própria escolha do veículo de socialização desses textos - periódico ou livro - se vincula à maneira como cada comunidade disciplinar se relaciona com o conhecimento que produz, quais os critérios que regem a legitimação do que pode/deve ou não ser publicado, qual o público que se busca alcançar. Os periódicos são defendidos pelas ciências físicas e biológicas pela maior possibilidade de revisão por pares, pela especialidade disciplinar que garantem e pela rápida comunicação, especialmente on line. As ciências humanas e sociais tendem a privilegiar o livro, assumindo que, mesmo sem os mecanismos usuais de avaliação, este veículo assume maior espaço de socialização, justamente porque circula além da especialidade, podendo atingir inclusive um público não-acadêmico. A avaliação, nesse caso, se desenvolve a partir de sua maior socialização. Mas de todo jeito, supomos reunir o que é considerado essencial, bem como o essencial para que essa essência seja compreendida: suas "bases". Por vezes, chegamos mesmo a considerar a existência de uma ordem de aprendizado desses saberes, uma ordem de leitura dos textos dessa biblioteca.

\footnotetext{
${ }^{4}$ Personagem de Elias Canetti, em o Auto-de-fé.
} 
As idéias de currículo mínimo, parâmetros curriculares, currículo nacional, ciência para todos atendem a essa expectativa: selecionar o que se supõe que irá garantir o acesso às bibliotecas legítimas ou fundamentais. Justamente porque têm uma forte vinculação com uma tradição do campo, adquirem legitimidade e apoio mesmo em grupos politicamente contrários aos partidos que viabilizaram a manutenção dessas propostas. Isso porque, muitas vezes, as críticas não são ao processo de formar coleções nessas orientações centralizadas, mas aos critérios utilizados para produzir tais coleções. Outros grupos buscam inserir seus "livros", seus saberes no que é projetado para todos. De forma geral, propõem princípios lógicos na tentativa de organizar os saberes em certa ordem entendida como melhor para todos.

Tal vínculo entre essas propostas e tradições educativas mais amplas pode ser ilustrado pelo recurso à literatura. Lima Barreto, no seu conto A Biblioteca, descreve bem o empenho de um pai em manter uma biblioteca com os livros clássicos capazes de formar seu filho em Química. Descreve, ainda, seu profundo sofrimento ao saber que o mesmo filho não aprenderá a ler e, portanto, não acessará àquele saber tão bem colecionado durante a vida do avô do menino, caracterizando a passagem de uma geração à outra, própria da formação disciplinar. De certa forma, não queremos perder nossos antepassados porque também não queremos que nos percam. Essa biblioteca passada de geração em geração expressa o dispositivo de colecionar que, como discute Canclini (1998), não só organiza e hierarquiza os bens simbólicos, mas diferencia aqueles que são capazes de entender a lógica da coleção. Aqueles que o fazem são identificados com essa coleção, são disciplinarizados.

Com as mudanças de cenários que nos fazem tentar apreender a fluidez de nossa época denominando-a pós-moderna, as antigas bibliotecas, tal qual a que Fausto Carregal guardou para seu filho, parecem não fazer mais sentido. Muitas vezes isso nos aflige, nos faz sentir como se perdêssemos o chão, um chão que julgamos nos impedir de cair no relativismo como quem cai do Paraíso. Tais bibliotecas são reconfiguradas por princípios que desfazem as coleções e, talvez, a própria idéia de colecionar. Primeiro, porque o deslocamento da legitimação do conhecimento na verdade e na justiça para o foco no desempenho, desenvolvido a partir do questionamento às formas científicas modernas de provar, traz para o campo científico uma nova relação com a tecnologia (LYOTARD, 1986). Esta passa a ser marcada pela possibilidade de gerar mais-valia e, dessa forma, re-introduzir recursos no processo científico para seu contínuo desenvolvimento. A estreita conexão estabelecida entre as performances necessárias ao desenvolvimento econômico e as performances produzidas 
por intermédio da introdução do avanço tecnológico no desenvolvimento científico propicia, como discute Lyotard (1986), a penetração das normas de organização do trabalho empresarial nas dinâmicas do trabalho científico. Para garantir o que se entende como desenvolvimento científico-tecnológico, não mais se defende a apropriação de conteúdos científicos. Estes são compreendidos como passíveis de serem acessados em bases de dados variadas, mas facilmente acessíveis pela transformação das informações de nossas bibliotecas em bytes. $\mathrm{O}$ foco do ensino-aprendizagem é deslocado para os desempenhos necessários ao processamento e acesso a tais bases de dados. Com a aceitação da lógica de que deve existir uma relação estreita entre educação, trabalho e produção científica, a eficiência no ensino e a eficiência nos demais campos são vistas como equivalentes, sendo medidas em termos de competências e habilidades para executar determinados desempenhos (LÓPEZ; LOPES, 2006).

Segundo, porque os hipertextos na internet, as constantes e ultra-rápidas desterritorializações aceleram as descoleções das bibliotecas. Canclini (1998) considera a agonia das coleções como sintoma de desvanecimento das classificações entre culto e popular, assim como o próprio desvanecimento disciplinar. A qual disciplina se vinculam os Estudos Culturais, indaga Canclini. Cabe situar uma disciplina - Antropologia, Filosofia, Sociologia - para tal? Essa circulação mais fluida e mais complexa faz com que novas identidades e hierarquias se constituam, caracterizadas pela obliqüidade (CANCLINI, 1998), novas disciplinas se formem. Por vezes, na tentativa de fazer frente a esse processo, nos prendemos à memória como se fosse ela mesma uma coleção e não, a constante reconstrução do passado na dinâmica entre lembrar, esquecer e recriar.

Uma das formas de entendermos esse processo acelerado de descolecionar, desterritorializar, reconfigurar é por intermédio do conceito de globalização. Mas gosto quando Appadurai (2000) opta por tratar a globalização como um fenômeno que não é novo. A globalização, na sua leitura, é uma produtora de fluxos disjuntivos há muito existentes. Os fluxos caracterizam os movimentos constantes de idéias, ideologias, pessoas, imagens, tecnologias, que apenas provisoriamente são vistos como estruturas ou organizações estáveis pela incapacidade de nossos dispositivos para identificar e lidar com o movimento. Esses fluxos, segundo o autor indiano, não são convergentes, não têm a mesma direção, velocidade, origem e mantêm entre si apenas relações disjuntivas. Tais fluxos hoje seriam apenas acelerados pelas novas tecnologias. Cabe busca investigar como essa aceleração amplia as 
possibilidades de interpretarmos de forma diferenciada tanto o tempo presente quanto o passado.

Mesmo no passado, as coleções foram montadas como para buscar produzir uma determinada ordem no caos. Talvez antes julgássemos que o caos era aparente e o esforço do conhecimento era descobrir a ordem oculta nessa aparência. Hoje mais facilmente se aceita a ordem como aparente. Mais facilmente identificamos os incansáveis colecionadores, inclusive os que montam bibliotecas de registros - a exemplo do personagem José em Todos os nomes, de Saramago - como alguém com uma angústia metafísica por não suportar que o caos rege o Universo. Alguém que busca incessantemente vencer essa angústia defendendo suas coleções tão bem ordenadas, mesmo que para penetrarem nessa ordem precisem de um fio de Ariadne atado ao tornozelo.

Por essa interpretação, é possível compreender a própria biblioteca de Fausto Carregal como não tão solidamente disciplinar, no que concerne ao conjunto de saberes. Também nela, fluxos de saberes se fazem, talvez em uma velocidade menor que não os faz tão notáveis. Todavia também nela estão Lavoisier, Camões e Euclides.

Mas com a aceleração dos processos de descolecionar, mais forte se faz a certeza de não existirem os livros-base, as bibliotecas fundantes capazes de nos identificar de uma vez por todas, ou pelo menos por um longo período de estabilidade. Isso nos possibilita olhar para o passado questionando a própria interpretação de que ele se fez - ou se faz - por intermédio de bibliotecas tão bem consolidadas.

A mim parece que a concepção de hibridismo pode nos ajudar a entender as descoleções e desterritorializações em nossas disciplinas e bibliotecas, se entendermos esses híbridos culturais não como um cenário pós-moderno, mas uma concepção para repensarmos a estabilidade tão bem assentada com que construímos a história.

Diante de tantas descoleções e do foco no desempenho, muitos apostam no fim das disciplinas. Mas com o conhecimento rizomático, as redes de conhecimento, a transdisciplinaridade, porque ainda somos tão disciplinares? Por que ainda investigamos as disciplinas? Por que nos organizamos disciplinarmente, inclusive na formação deste periódico e de seus artigos? 
Defendo que isso acontece porque não está em foco o sentido epistemológico de disciplina, como mencionei anteriormente: conjuntos de saberes, bem como métodos e dispositivos de pensamento comuns capazes de produzir e reproduzir esses saberes. Mas as disciplinas como construções sociais que atendem a determinadas finalidades. Reúnem sujeitos em determinados territórios, sustentam e são sustentadas por relações de poder que produzem saberes.

Exemplifico essa questão propondo que pensemos nos Grupos de Trabalho (GTs) da Associação Nacional de Pesquisa e Pós-graduação em Educação (Anped). Do ponto de vista epistemológico, ao menos de certa epistemologia, tais GTs são classificados em disciplinares e não-disciplinares. Há os defensores das duas formações. Há quem defenda também a distinção entre o que é visto como base fundante da educação - filosofia, sociologia, psicologia, antropologia - e o que é visto como campo aplicado dessa mesma área - currículo, didática, formação de professores. Há aqueles que supõem superar as disciplinas organizando GTs com base em pesquisas e sua articulação com movimentos sociais.

$\mathrm{Na}$ perspectiva sócio-histórica, contudo, tal distinção entre disciplinar e nãodisciplinar se esvai, perde o sentido. Todos os GTs e todos esses campos de saber são igualmente disciplinares, com constituições sociais e históricas próprias, lutas, conflitos, acordos. Nessa perspectiva, não há um saber a priori que, uma vez dominado, nos faculta a ser de uma disciplina. Mas construímos este saber no processo de nos tornarmos disciplinares. Nesse processo, entendo que igualmente se incluem as inter-relações entre saberes, os processos de integração (LOPES, 2008). Por diferentes lutas políticas hegemonizamos campos disciplinares e constituímos nossas identidades nessas lutas.

$\mathrm{Na}$ constituição de hegemonias, nos formamos como vontades coletivas, capazes de defender certas demandas (LACLAU, 2005). Uma demanda social é caracterizada por Laclau (2005) como solicitações e expectativas de grupos sociais que, uma vez não atendidas, podem se transformar em reivindicações em defesa das quais variados grupos se unem em uma luta política. Uma vez definidas as demandas em jogo na política é que os grupos em torno dessas demandas são definidos.

Assim, não há identidades políticas estabelecidas a priori, sejam elas decorrentes de posições dos sujeitos em relação à classe, gênero, raça ou mesmo disciplinas. Não há identidades políticas constituídas previamente ao processo articulatório, pois, como discute 
Mouffe (2001), a prática política em uma sociedade democrática constitui as identidades políticas em um terreno precário e sempre vulnerável.

Nessa perspectiva, uma disciplina não se vincula ao processo de fixação de identidades. Quem e como os sujeitos são posicionados como membros de uma comunidade disciplinar dependem dessa luta política, e não do que possa ser compreendido como "saberes em si”. As vontades coletivas dessas comunidades são formadas a partir de uma articulação hegemônica na qual tradições constituem os sujeitos dessa luta.

Recorro aqui ao sentido de tradição de Chantal Mouffe (1996): uma inserção histórica em determinados discursos, neles incluídas as práticas e os jogos de linguagem, que nos constituem como sujeitos. Grupos de pessoas reconhecem certas formas políticas de se organizar em comunidades em função de tradições, ou fragmentos de tradições, que têm em comum. Tais tradições também condicionam seus modos de vida e suas formas de interpretar. Não se trata, no entanto, de tradicionalismos que fixam a luta política, mas tradições sujeitas a diferentes interpretações nessa mesma luta.

Caso focalizemos especificamente o campo do currículo, as tradições curriculares - discursos, por exemplo, sobre a seleção e a organização curricular, a cultura e o conhecimento escolar - situam contornos para as comunidades de especialistas que se organizam em torno de determinadas demandas educacionais. Como diferentes sujeitos preenchem, por exemplo, o significante vazio ${ }^{5}$ qualidade de ensino, dependem de suas tradições curriculares construídas historicamente em comunidades específicas. As comunidades disciplinares, cuja constituição é vinculada à organização curricular disciplinar e a toda uma série de ações sociais decorrentes das disciplinas como construções sóciohistóricas, lutam politicamente por certas demandas e se articulam com outras comunidades em função da possibilidade de atender a essas mesmas demandas. No processo de articulação, tanto suas identidades como suas demandas se hibridizam e têm seus sentidos reconfigurados.

Por isso considero que admitir identidades híbridas não implica desconsiderar os traços das tradições que permanecem em nossos discursos, as negociações que fazemos com tais tradições, as negociações com nossas múltiplas bibliotecas - de livros, de teorias, fragmentos do cotidiano, e o que mais seja. Ou mesmo de suas descoleções.

\footnotetext{
${ }^{5}$ Para uma discussão teórica sobre os significantes vazios e sua importância para a luta política, ver Laclau (1996).
} 
O hibridismo no campo do currículo no Brasil, tantas vezes afirmado (LOPES; MACEDO, 2003), é um exemplo desse processo. Até aproximadamente o fim dos anos 1970, o campo teve como marca central os estudos de caráter administrativo-científico. Os enfoques críticos atingiram seu ápice nos anos 1990, passando também a receber contribuições de enfoques pós-estruturalistas, pós-coloniais e pós-modernos. Por vezes, os enfoques críticos, e mesmo os enfoques pós-críticos ${ }^{6}$, não produziram a superação da característica um tanto prescritiva que foi marca dos trabalhos na vertente instrumental, mas ainda assim contribuíram, e muito, para a complexificação do entendimento de currículo, bem como para a ampliação e diversificação dos objetos de pesquisa. A maturidade e a fertilidade do campo são facilmente percebidas na produção bibliográfica (LOPES; MACEDO; PAIVA, 2006).

Novos aportes teóricos, da filosofia, da sociologia, dos estudos culturais, são incorporados, de maneira a tentar construir uma problemática de pesquisa específica, constituindo um hibridismo importante para a abertura de novos enfoques, ainda que, também, esse hibridismo contribua para tornar o currículo tão ambíguo e multifacetado que parece perder certa sintonia com as tradições do pensamento curricular. A meu ver, o enfrentamento dessa problemática não passa pela tentativa de tratar esse hibridismo característico do campo como negativo. Como diz Laclau (1996, p.65), só uma identidade conservadora, fechada em si mesma, poderia experimentar a hibridização como uma perda. $\mathrm{O}$ importante é sermos capazes de analisar criticamente esses híbridos culturais tendo em vista compreender que objeto de pesquisa construímos e como formulamos nossas questões de pesquisa.

A postura crítica em relação aos híbridos culturais passa, a meu ver, pela sintonia do campo com as tradições do pensamento curricular e pedagógico de forma mais ampla. Não no sentido de louvá-las ou delas extrair uma linha contínua de evolução dos saberes ou mesmo uma direção para a luta política. Mas visando a compreender que sentidos dessas tradições negociam com os processos de significação desenvolvidos na atualidade. Isso implica incluirmos em nossa agenda uma constante interação com as tradições do próprio campo.

\footnotetext{
${ }^{6}$ Utilizo a expressão aqui para denominar genericamente os enfoques pós-estruturalistas, pós-coloniais e pósmodernos. Vale a ressalva, porque seria possível continuar utilizando a denominação "enfoques críticos", salientando que o sentido de "crítica" é que se modifica.
} 
Não acho que o campo deva se fechar em uma fronteira disciplinar específica, mesmo porque não considero que isso seja possível, tendo em vista a concepção de disciplina com a qual trabalho. Mas preocupa-me que não sejamos capazes de perceber em discursos atuais traços do eficientismo social ou do progressivismo hibridizados a teorias de outras áreas. Preocupa-me que não investiguemos com que sentidos das tradições engendradas a partir dos trabalhos de Anísio Teixeira e Paulo Freire negociamos nos dias atuais. Ou como articulamos discursos estruturalistas e pós-estruturalistas, modernos e pós-modernos.

Por intermédio da valorização do entendimento das tradições do pensamento curricular, volto assim às bibliotecas, porém tentando questionar tanto os essencialismos quanto a fixação de suas identidades. A definição do que entendemos por tradição de um campo disciplinar depende dessa negociação de sentidos que o próprio campo estabelece. Conceber que são múltiplas as bibliotecas capazes de nos formar e que, politicamente, reconstruímos seus sentidos, na medida em que construímos nosso campo disciplinar, parece ser uma forma de concebermos de forma menos fixa nossas disciplinas. De percebermos, simultaneamente, porque nos mantemos disciplinares. Mas são disciplinas sem certezas. Por mais que desejemos ardorosamente, não há um fio de Ariadne a nos guiar, uma biblioteca fixa do passado para louvar ou para garantir o universo do saber e nossos filhos não necessariamente lerão a biblioteca que deixarmos. Também não há certeza de que se lembrarão de nós. Essas coleções são feitas e refeitas cotidianamente, novas leituras e novos sentidos são atribuídos, híbridos culturais são construídos, ações políticas em um terreno de incertezas são produzidas. Conviver com a incerteza do jogo político parece ser o que nos resta. Mas, ao mesmo tempo, pode ser o que nos fascina. E em parte, a participação nesse jogo depende de entendermos, no campo educacional, que a construção de uma biblioteca é ela mesma política, esteja ela nas estantes, nas pastas de um HD ou apenas em nossa imaginação.

\section{REFERÊNCIAS}

APPADURAI, A. Grassroots globalization and the research imagination. Public Culture, V. 12, n.1, p.1-19. 2000.

BORGES, J. L. Ficções. São Paulo: Círculo do Livro, 1975. 
CANCLINI, N. G. Culturas híbridas: estratégias para entrar e sair da modernidade. São Paulo: Edusp, 1998.

CANETTI, E. Auto-de-fé. São Paulo: Cosac-Naify, 2004.

LACLAU, E. Emancipation(s). London: Verso, 1996.

LACLAU, E. La razón populista. Buenos Aires: Fondo de Cultura Económica, 2005.

BARRETO, A. H. A. L. Biblioteca. In: Histórias e sonhos. São Paulo: Brasiliense, 1956, p. 139-150.

LOPES, A. C. Currículo e epistemologia. Ijuí: Unijuí, 2007.

Políticas de integração curricular. Rio de Janeiro: EdUERJ/Faperj, 2008.

.; MACEDO, E. The curriculum field in Brazil in the 1990s. In: PINAR, W. F. (Ed.). International Handbook of Curriculum Research. New Jersey: Lawrence Erlbaum Associates, 2003. p. 185-204.

, MACEDO, E.; PAIVA, E. Mapping Researches on Curriculum in Brazil. Journal of the American Association for the Advancement of the Curriculum, Wisconsin, EUA, v. 2, n. 1, p. 1-30, 2006.

LÓPEZ, S. B.; LOPES, A. C. 2006. A performatividade na política de currículo: o caso do ENEM. Anais do XIII ENDIPE. Recife: CD-Rom. 15 p.

MOUFFE, C. O regresso do político. Lisboa: Gradiva, 1996.

Identidade democrática e política pluralista. In: MENDES, C.; SOARES, L. E. (Orgs.). Pluralismo cultural, identidade e globalização. Rio de Janeiro: Record, p. 410-430, 2001.

SARAMAGO, J. Todos os nomes. São Paulo: Companhia das Letras, 1997. 


\section{ALICE CASIMIRO LOPES}

Professora da Universidade do Estado do Rio de Janeiro (UERJ), pesquisadora do CNPq e coordenadora do grupo de pesquisa Currículo: sujeitos, conhecimento e cultura, www.curriculo-ueri.pro.br E-mail alice@curriculo-ueri.pro.br

Recebido em: 10/03/2008 Publicado em: 20/10/2008 